\title{
Mudanças climáticas e seus efei- tos no Litoral Médio do Rio Grande do Sul
}

$\begin{array}{ll}\text { Stefania Hoff Ambos } & \text { Mestranda no Programa de Pós-Graduação Mestrado } \\ \text { Profissional em Ambiente e Sustentabilidade (UERGS). }\end{array}$

E-mail: stefaniah.a@gmail.com

Doutor em Ciências, Professor na Universidade Estadual

Ricardo S. P. Mello do Rio Grande do Sul (UERGS), Campus Regional VII.

E-mail: rspmello@gmail.com

Doutoranda no Programa de Pós-Graduação em Sociolo-

Amanda N. da Silva gia (UFRGS).

E-mail: amanda.ndsilva@gmail.com Observatório de Políticas e Ambiente (ObservaCampos). Unidade de São Francisco de Paula, Universidade Esta-

Patrícia Binkowski dual do Rio Grande do Sul, São Francisco de Paula, RS, Brasil.

E-mail: patinski77@yahoo.com.br

Recebido em: 15 mar. 2017. Revisado: 24 mar. 2017. Aceito: 02 abr. 2017.

DOI: http://dx.doi.org/10.21674/2448-0479.34.683-693

\section{Resumo}

As discussões sobre as mudanças climáticas têm sido muito frequentes nos últimos anos, devido aos efeitos estarem atingindo o ambiente, a sociedade e a economia. Os efeitos das mudanças do clima geralmente são abordados em uma escala global, porém, há a necessidade de se explicar, em escala regional, os efeitos que o clima tem ocasionado em consonância com os aspectos socioeconômicos regionais. Identificar os efeitos climáticos em escala regio- 
nal e traçar sua influência na economia e na sociedade é um desafio para o planejamento de políticas de mitigação e adaptação ao clima. Neste contexto, o presente trabalho tem como objetivo identificar os impactos sociais, ambientais e econômicos das mudanças climáticas no Litoral Médio do Rio Grande do Sul. Foram realizados levantamentos bibliográficos e registros documentais sobre o histórico de eventos climáticos intensos com danos socioeconômicos ocorridos no Litoral Médio. A identificação das projeções climáticas para o sul do Brasil foi realizada através de relatórios governamentais, em que foram analisadas as tendências anuais e das estações. Para a caracterização socioeconômica e ambiental foi realizada pesquisa bibliográfica e quantitativa sobre a demografia do Litoral Médio. Foram identificados 132 eventos climáticos ocorridos de 1972 a 2015, que causaram desastres no Litoral Médio. Esses eventos foram divididos em 4 categorias sintéticas que são: chuvas intensas, seca, granizo e vendaval. As projeções climáticas identificadas foram realizadas para o período de 2071 - 2100 em que se identifica a tendência de um período mais seco, com 10 a $20 \%$ menos pluviosidade em relação aos registros climatológicos de 1961-1990. Porém, nos outonos se prevê aumento de precipitação que pode variar de 10 a $40 \%$. Em relação à caracterização socioeconômica identificou-se que os municípios do Litoral Médio possuem populações em vulnerabilidade social que estão sendo impactadas frequentemente por desastres, como as enchentes ocorridas em Tapes nos anos de 2009, 2012, 2014 e 2015 que danificaram residências. Assim, se faz necessário estimular um amplo debate com as sociedades locais, poder público e as instituições para que sejam elaboradas e aplicadas políticas públicas para a mitigação e adaptação a tais mudanças climáticas.

Palavras-chave: Serviços Ambientais. Ecossistema. Delta do Jacuí. 


\section{Introdução}

As mudanças climáticas tem sido uma temática bastante discutida no século XXI. O debate sobre mudanças climáticas iniciase nos anos 1990, onde se discutia, principalmente, sobre a redução da emissão dos gases de efeito estufa para conter o aquecimento do planeta. Em função disso, foram assinados por países diversos tratados mundiais como o Protocolo de Kyoto em 1998, que designavam metas a serem cumpridas por estes países para a redução das emissões.

Atualmente sabe-se que pouco se cumpriu dessas metas propostas pelas nações. O crescimento econômico continua sendo incentivado pelos países e nesse tempo poucas tecnologias foram desenvolvidas para que os efeitos relacionados às mudanças do clima pudessem ser revertidos. A partir disso, as discussões se voltaram para o desenvolvimento de mecanismos para a adaptação e mitigação aos efeitos das mudanças climáticas.

Alguns efeitos das mudanças climáticas estão relacionados as emissões de gases de efeito estufa na atmosfera, principalmente gás carbônico $\left(\mathrm{CO}_{2}\right)$, que são elementos que regulam a temperatura e o clima do planeta. Entre as principais mudanças vistas estão o aumento da temperatura da Terra, mudanças do $\mathrm{pH}$ dos oceanos, derretimento das calotas de gelo, elevação do nível do mar, diminuição das populações naturais da flora e da fauna, mudança nos padrões de ocorrência e virulência das doenças, além de secas e tempestades mais intensas (CASTRO, 2016).

Novos problemas socioeconômicos e políticos estão elevando a prioridade de questões relativas à segurança ecológica nas políticas públicas como os problemas com recursos hídricos, incer- 
tezas à segurança energética e à propagação geográfica de doenças. Efeitos climáticos trazem grandes desafios à sociedade, como por exemplo, saber lidar com uma nova atmosfera, com o aumento dos oceanos, uma biodiversidade diferente, recursos limitados e territórios modificados (HODSON; MARVIN, 2014).

Eventos climáticos extremos começaram a acontecer com uma substancial frequência no início do século XXI no sul do Brasil (MARENGO, 2006). A ocorrência desses eventos chama a atenção dos governos para a importância de se criarem planos de prevenção a estes riscos até então ausentes. Os efeitos desses eventos climáticos extremos são perdas econômicas e até de vidas, como ocorreu no último dia 12 de março no município de São Francisco de Paula/RS, onde 5 bairros foram devastados por um tornado, ocorrendo a morte de um jovem. A ocorrência desses eventos demanda a ação de diversos entes governamentais como defesa civil, corpo de bombeiros, prefeituras, Estado, entre outros.

Os municípios com menos recursos financeiros localizados em regiões menos favorecidas economicamente são os que mais sofrem com os efeitos de um desastre. Com essa situação somada à existência de populações vulneráveis localizadas em áreas de risco é que emerge a necessidade de adaptação dessas regiões aos efeitos climáticos. Nesse contexto foi proposto este estudo sobre impactos das mudanças climáticas no Litoral Médio, em foi feito uma abordagem sobre os desastres climáticos já ocorridos, a situação socioeconômica atual dos municípios que compõem o Litoral Médio e a perspectivas futuras através de projeções climáticas.

O Litoral Médio do Rio Grande do Sul está localizado no bioma Pampa, característico por ser um ecossistema campestre com grande riqueza de espécies, além de abrigar outros ambientes como paisagens florestais, banhados e matas de restinga e butiazais. A 
maior parte do bioma Pampa foi modificada pela atividade humana, sendo que é uma região que sustenta ecossistemas únicos de grande importância para a conservação de espécies (BENCKE et al, 2016).

A população total do Litoral Médio nos municípios selecionados para este estudo é de 965.015 , pessoas segundo dados do censo demográfico do IBGE realizado em 2010. O processo de colonização do litoral do Rio Grande do Sul se deu a partir do século XVIII com os lusitanos. A região é marcada por uma cultura local em que houve uma mescla entre as culturas indígena, negra e açoriana, além das imigrações mais recentes, no século XIX, de italianos e alemães. Esses povos que se desenvolveram possuem uma forte relação com elementos da biodiversidade do litoral médio o que torna as características socioeconômicas, culturais e ambientais nessa região inestimável (CHOMENKO, 2016).

Os principais usos econômicos da região de acordo com o Relatório do Zoneamento Ecológico Econômico (ZEE) do Litoral Médio são orizicultura, lavouras temporárias que incluem a soja, a cebola e o milho, silvicultura, pecuária, energia eólica, mineração principalmente de areia, incluindo também saibro, argila, titânio, ferro e ilmenita. Neste contexto, o presente trabalho tem como objetivo identificar os impactos sociais, ambientais e econômicos das mudanças climáticas no Litoral Médio do Rio Grande do Sul.

\section{Metodologia}

A escolha dos municípios que compõe este estudo partiu da definição de Litoral Médio pela Fundação Estadual de Proteção Am- 
biental Henrique Luiz Roessler (FEPAM- RS), que o define como sendo composto pelos municípios no entorno da Laguna dos Patos e abrange vinte e quatro municípios. Neste estudo foram escolhidos os municípios que possuem faixa costeira: Barra do Ribeiro, Tapes, Arambaré, Camaquã, São Lourenço do Sul, Turuçu, Pelotas e Rio Grande na parte oeste, Viamão, Capivari do Sul, Palmares do Sul, Tavares, Mostardas e São José do Norte na parte leste (Figura 1).

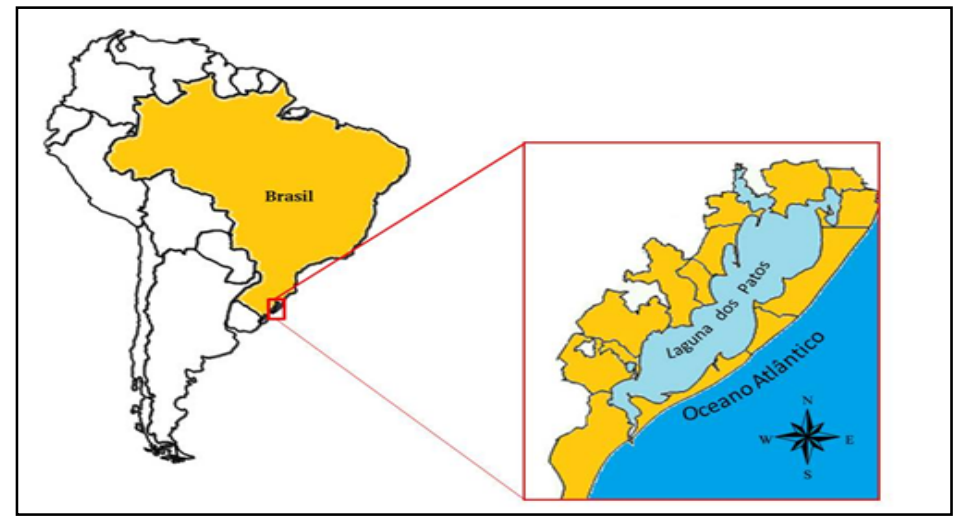

Figura 1 - Localização do Litoral Médio do Rio Grande do Sul. Fonte: AMBOS (2016).

O histórico de eventos climáticos que afetaram a região sul do Brasil foi feito através de análise de documentos e noticiários de jornais e sites. O histórico foi feito através de consulta ao Sistema Integrado de Informações sobre Desastres (S2ID) que integra diversos produtos da Secretaria Nacional de Proteção e Defesa Civil (SEDEC); o banco de dados consultado possuía informações do período 1940 a 2015. As categorias de eventos climáticos que foram registradas nesta plataforma foram: alagamentos, inundações, en- 
chentes, chuvas intensas, tempestade de granizo, vendavais, ciclones, ressacas.

Foram consultadas as projeções climáticas para o período de 2071 - 2100 da região sul do Brasil através de relatórios governamentais do Intergovernmental Panel on Climate Change (IPCC). Assim foi realizado prognóstico para o Litoral Médio do Rio Grande do Sul das áreas afetadas com as mudanças climáticas a partir das previsões mundiais existentes.

\section{Resultados e Discussão}

Foram identificados 132 eventos climáticos ocorridos de 1972 a 2015 que causaram efeitos desastrosos no Litoral Médio. Tais eventos foram divididos em 4 categorias sintéticas que são: chuvas intensas, seca, granizo e vendaval. Foi elaborada uma série temporal com o Histórico de Desastres Relacionados ao Clima no Litoral Médio, com cada tipo de desastre e os municípios atingidos (Figura 2).

Ao analisar este histórico de desastres (Figura 2) é possível notar que a primeira linha temporal, vinte primeiros anos - de 1972 a 1992 - a quantidade de municípios atingidos é muito menor que de 1993 a 2013, vinte anos depois. O que se observa é um aumento frequente no número de desastres, isso gera preocupação, pois muitos municípios vêm sendo atingidos, causando prejuízos socioeconômicos a estas populações. 


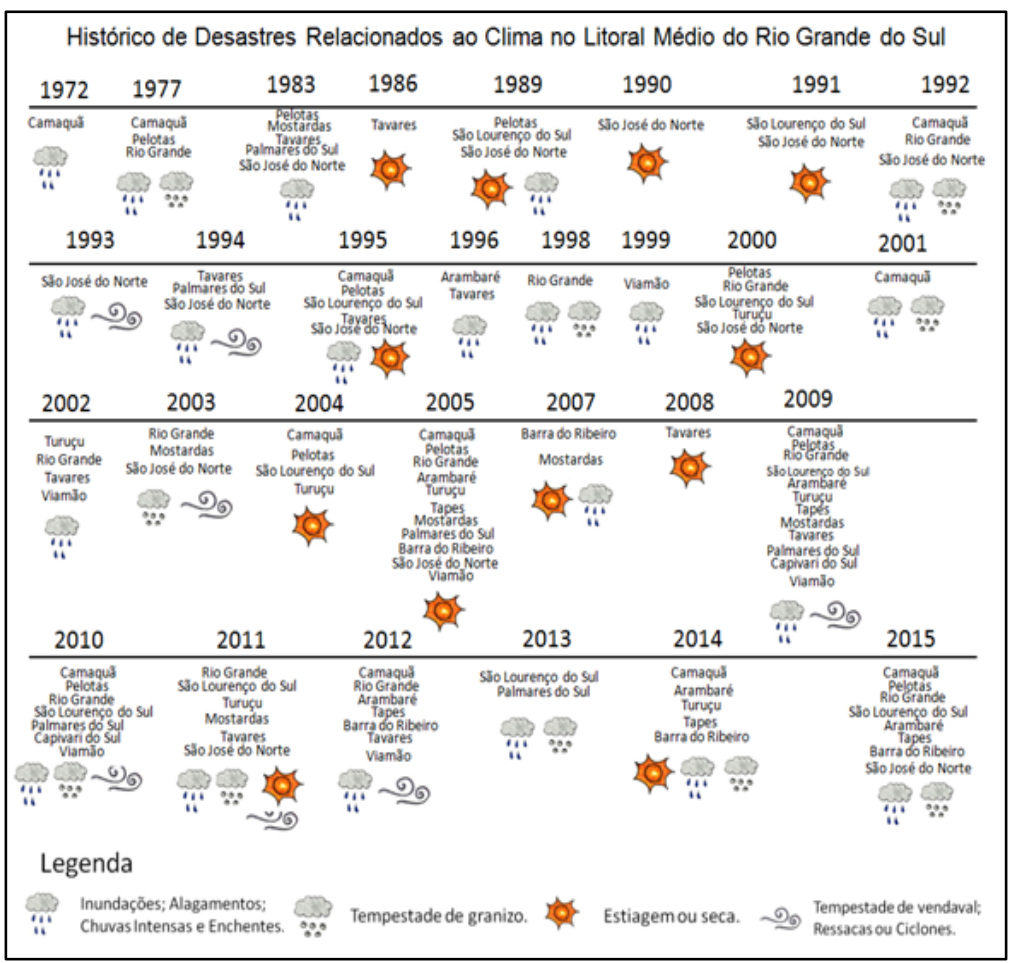

Figura 2 - Histórico de desastres relacionados ao clima no Litoral Médio. Fonte: AMBOS (2016).

As projeções climáticas do IPCC (2000) identificadas foram de 2071 - 2100, a tendência anual e as estações do ano, na análise anual verificou-se a tendência de um período mais seco, de 10 a $20 \%$ menos pluviosidade em relação aos registros climatológicos de 1961-1990. Porém, no outono prevê aumento de precipitação que pode variar de 10 a 40\%. Nesses períodos de outono é possível que aconteçam desastres relacionados a chuvas intensas e enxurradas. No período da primavera, no entanto, observa-se um período com 
menor pluviosidade, isso pode indicar que nessa estação pode haver déficit de água.

A partir dessas previsões em que se sabe que haverá menor pluviosidade é preciso que haja planejamento entre os municípios para que se estimule a economia de água através de sistemas de coleta da água da chuva ou reaproveitamento das águas cinza, principalmente no perímetro urbano. Para o meio rural a existência de açudes para a captação da água da chuva nos períodos do ano em que haja maior incidência de chuvas é necessário para o abastecimento da agricultura.

\section{Conclusão}

O histórico de eventos climáticos extremos com ocorrência frequente nos mesmos locais demonstra que a gestão ambiental dos municípios do Litoral Médio está precária e deve ser dada mais atenção à ocorrência desses eventos climáticos buscando prevenilos. Os desastres ocorridos ocasionaram impactos sociais e econômicos, dessa forma a prevenção a esses eventos é a melhor forma de superar a essas catástrofes.

As ações de governança devem promover o desenvolvimento de políticas que repensem os modos de consumo atuais, em que o uso indiscriminado dos recursos naturais vem antes da conservação do ambiente. Ações de prevenção às mudanças climáticas devem buscar desenvolver políticas para o desenvolvimento sustentável.

As previsões climáticas podem ser usadas como uma ferramenta de gestão para que se tomem medidas de mitigação e adaptação às mudanças climáticas. Através delas é possível planejar a 
região para que quando ocorra um evento extremo ela já esteja preparada.

Ao longo dos últimos anos mais populações estão sendo afetadas pelas mudanças climáticas. Sabendo disso os governos não podem mais adiar medidas de adaptação ao clima e mudanças nos padrões de desenvolvimento, ao ocorrer um desastre as perdas econômicas e sociais são muito maiores do que se tivesse sido prevenido. A adaptação destas regiões a estas circunstâncias deve ser crucial para que haja o desenvolvimento social, ambiental e econômico.

\title{
Referências
}

\begin{abstract}
AMBOS, S.H. Efeito das Mudanças Climáticas sobre a Vulnerabilidade Social do Litoral Médio do Estado do Rio Grande Do Sul [trabalho de conclusão de curso]. Tapes: Universidade Estadual do Rio Grande do Sul, Curso de Bacharelado em Gestão Ambiental, 2016.
\end{abstract}

BENCKE, G. A. et al. O que é o Pampa? In: BENKE, G. A.; CHOMENKO, L (org.) Nosso Pampa Desconhecido. Porto Alegre, RS: Fundação Zoobotânica do Rio Grande do Sul, p. 17- 20, 2016.

CASTRO, C. B. Mudanças Climáticas. In: GERLING, C. (Org). Manual de Ecossistemas Marinhos e costeiros para educadores. Santos, SP: Editora comunnicar, p. 44- 45, 2016.

CHOMENKO, L. Litoral médio: Aspectos socioeconômicos e culturais. Projeto RS Biodiversidade. Natureza em Revista, Ed. 14. p. 80- 83. mar, 2016.

HODSON, M; S. MARVIN. Ecocidades transcendentais ou segurança ecológica urbana? In: MOSTAFAVI M.; DOHERTY G. (Org.) 
Urbanismo Ecológico. Barcelona: Editorial Gustavo Gili, p. 208215, 2014.

INSTITUTO BRASILEIRO DE PESQUISA E ESTATISTICA. Censo Demográfico 2010. Características da população e dos domicílios: resultados do universo. Rio de Janeiro: IBGE, 2011.

MARENGO, J. A. Mudanças Climáticas Globais e seus Efeitos sobre a Biodiversidade: Caracterização do Clima Atual e Definição das Alterações Climáticas para o Território Brasileiro ao Longo do Século XXI. Biodiversidade 26 Brasília - DF. 2006. 